This item was submitted to Loughborough's Research Repository by the author.

Items in Figshare are protected by copyright, with all rights reserved, unless otherwise indicated.

\title{
Citizen, consumer, citimer: The interplay of market and political identities within contemporary football fan cultures
}

PLEASE CITE THE PUBLISHED VERSION

https://doi.org/10.1177/1469540517744692

\section{PUBLISHER}

(C) The authors. Published by SAGE Publications Ltd

\section{VERSION}

AM (Accepted Manuscript)

\section{PUBLISHER STATEMENT}

This work is made available according to the conditions of the Creative Commons Attribution-NonCommercialNoDerivatives 4.0 International (CC BY-NC-ND 4.0) licence. Full details of this licence are available at: https://creativecommons.org/licenses/by-nc-nd/4.0/

\section{LICENCE}

CC BY-NC-ND 4.0

\section{REPOSITORY RECORD}

Numerato, Dino, and Richard Giulianotti. 2019. "Citizen, Consumer, Citimer: The Interplay of Market and Political Identities Within Contemporary Football Fan Cultures". figshare. https://hdl.handle.net/2134/31898. 
Citizen, Consumer, Citimer: The Interplay of Market and Political Identities within

Contemporary Football Fan Cultures

\section{Dino Numerato}

Department of Sociology, Faculty of Social Sciences, Charles University, Prague, Czech Republic

\section{Richard Giulianotti}

School of Sport, Exercise \& Health Sciences, Loughborough University, UK and Department of Sports, Physical Education and Outdoor Studies, University College of Southeast Norway

Corresponding author

Dino Numerato, Department of Sociology, Faculty of Social Sciences, Charles University, Prague, U Kř́žze 8, 158 00, Praha 5, Czech Republic 


\title{
Citizen, Consumer, Citimer: The Interplay of Market and Political Identities within
}

\author{
Contemporary Football Fan Cultures
}

\begin{abstract}
:
This paper examines how football, sport and other cultural fields are characterized by complex interrelations between 'citizen' and 'consumer' identities. Our analysis centres specifically on critically examining and developing the concept of 'citimer' (citizenconsumer) with respect to activist supporter groups within European professional men's football. First, to establish the structural and cultural context for our analysis, we argue that the emergence of citizen-consumer identities in football has been driven by five underlying processes: globalization, commodification, securitization, mediatization, and postmodernization. Critical football fan movements have responded to these changes through greater reflexivization and politicization. Second, drawing on the broad academic literature, we develop the concept of the citizen-consumer (or 'citimer') and introduce its relevance to football. Third, to provide a more nuanced understanding of the citizen-consumer, we explore how this 'citimer' identity is constructed in two ways: 'from below' (by fan groups themselves at everyday level) and 'from above' (by clubs, governing bodies, media and other powerful forces within the football system). In both instances, we find that the citizen and consumer aspects of the citimer identity are interrelated in complex ways. Fourth, we conclude by highlighting the political reflexivity of citimers, and areas for future research. Our analysis draws on extensive data collection: with football supporters and officials in the Czech Republic, England and Italy, and at the wider European level; and, through access to diverse primary and secondary documents (e.g. policy papers, fanzines, and online forums). Our findings may be applied to examine citimer identities, practices and social relations not just within football and sport, but in many other cultural fields, such as art, communication, drama, fashion, film, and music.
\end{abstract}

Keywords: citimer, citizen, consumer, football, fan, reflexivity

\section{Introduction}

“Dear Mr. Jenkins, It's a real shame that we have to do this. That normal, everyday football supporters have to write to Chief Executive of a bank to ask for his help. Yet this is a necessary step. A step that we hope will bring great benefits to you and your organization and to the many hundreds of thousands of football supporters who need you to intervene on their 
behalf. You see, football has a problem. A big one that is getting worse. Football supporters, quite simply, are being priced out."1

This is a quote from a letter, addressed to the CEO of Barclays Bank on 27 September 2014, and written by two groups, Spirit of Shankly and the Blue Union, which represent football fans at the major English Premier League clubs, Liverpool FC and Everton FC, respectively. The letter sought to put pressure on Barclays Bank, then the main Premier League sponsors, to reduce ticket prices, in particular for supporters of the 'away' (visiting team) at football matches. The campaign had results: the bank officially recognized the supporters' request, while Barclays' Head of Global Sponsorship acknowledged the contribution of football fans in generating atmosphere and passion inside stadiums, and called for the Premier League to act on prices. ${ }^{2}$ Several months later, Premier League clubs agreed a ticket price-cap of $£ 30$ for away fans, beginning in the $2016 / 2017$ football season. ${ }^{3}$

The letter represents more than an anecdotal incident, and was instead an integral part of a three-year campaign, 'Twenty's Plenty'4, led by the English Football Supporters Federation. Spread in large part by social media, the campaign mirrored much broader techniques of resistance and contestation used in recent years by different European fan groups against commercial influences upon contemporary football culture. These expressions of discontent are not motivated purely by material concerns, but represent instead a much wider struggle over the identities of football supporters and the politics of the game. Furthermore, in registering the sophisticated campaigning tactics of fan groups, the letter provides testimony to the complex and peculiar relationships between critically engaged football fans and consumer culture, and to the ties and tensions between consumption and citizenship that are found in sport and other commercialized realms of global culture. In this regard, the civic engagement of football fans has strong continuities with, and contributes 
significantly to, forms of critical, political, and ethical consumerism that are observable in other social spheres and frequently framed by the citizen-consumer concept.

In examining the interconnections between consumption and citizenship, this paper provides an empirically informed theoretical elaboration of the concept of the citizenconsumer (or 'citimer'). Our analysis goes beyond basic citizen-consumer dichotomies, to identify and to examine instead the different kinds of citizen-consumer constellation. Our substantive focus is on football, an ideal cultural field for developing analysis of the citizenconsumer: elite-level men's professional football has long held strong forms of 'citizen'-based identity among supporters, while also promoting consumer-based relationships with fans and wider 'markets' since at least the late 1980s. This emphasis on the 'citizen' dimension of fandom moved mainstream public debates on football spectators away from 'hooliganism' issues, to focus instead on fans as actors with political and social rights in the decisionmaking processes of football clubs, associations and communities.

In what follows, we examine the key processes that contribute to the construction of citizen-consumer (citimer) identities in contemporary football cultures. In doing so, we seek to advance significantly the theoretical understanding of the citizen-consumer (citimer) concept. Thus, we argue that our theorization of citizen-consumer identities within football may be applied to other major sports, such as American football, baseball, basketball, cricket, and the different rugby codes, as well as across other popular cultural fields such as music, television, film, cuisine, and fashion.

Our primary focus is on the active minority of critically engaged football fans, particularly those who participate in different ways within supporter movements, campaigns, demonstrations, and/or critical fan-produced media (such as 'fanzines', online message boards, and other social media platforms), and on their interactions with football clubs and football associations. Like the wider corpus of football fans, these critically-engaged 
supporters are not socially homogenous, but are instead differentiated along intersecting lines of stratification (notably class, age, gender, sexuality, [dis]ability, and location), cultural and lifestyle tastes, values, political opinions and approaches towards consumption in different social fields. For reasons of brevity, our discussion focuses primarily on the final issue here, on the critical relationships of these fan groups to consumption. Our analysis is founded upon extensive ethnographic and interview research, undertaken in 2013-15, into football fan activism and its impact on football clubs and football associations in the Czech Republic, England, and Italy, as well as at the wider European level.

Our analysis is organized into four main parts. First, we set out the structural and cultural context for the emergence of citizen-consumer identities within contemporary football culture. Second, to situate our analysis in the academic context, previous research on the citizen-consumer concept is discussed. After setting out our research methods, we provide, third, an empirically informed discussion of the nuances and constellations of the 'citimer' concept. Finally, we assess the potential usage of the citimer concept outside of the field of football.

\section{Context: Football's Structural and Cultural Transformation}

The background to the emergence of football fan activism and to contemporary citizenconsumer identities lies in the major structural and cultural changes that have occurred within elite men's football, particularly in Western Europe, since the late 1980s. Serving to embed football firmly within global consumer culture, these transformations have been driven by five wider interrelated processes, particularly in the global North. Briefly summarized, these processes are as follows: 
- First, contemporary globalization has featured intensified transnational connectivity and global flows of ideas, images, people, commodities and services (Appadurai, 1990; Robertson, 1992).

- Second, commodification - the conversion of people, services, ideas, and objects into 'commodities' with market value - has been closely associated with the rise of neoliberal capitalism, including global free trade and financial networks, privatising of public services, and deeper social inequalities (Harvey, 2005; Walsh \& Giulianotti, 2007).

- Third, securitization has been marked by the rapid spread of security technologies, measures and strategies to monitor and control diverse social spaces (Klauser, 2017).

- Fourth, mediatization has featured the growing societal presence and influence of mass and social media (cf. Deacon and Stanyer, 2014).

- Fifth, postmodernization has been marked by the spread of postmodern social processes, such as, the erosion of modern boundaries (e.g. high/low culture, producer/consumer), the mass media's growing cultural influence, and the rise of the 'new middle classes' (Bauman, 1992; Beck et al., 1994).

In football, these interrelated processes have been evidenced in manifold ways. To summarize very briefly, these have included:

- Vast rises in the commercial values of top clubs, tournaments, players, and television contracts for fixtures.

- Transnational media coverage of tournaments across television, digital and online platforms.

- $\quad$ A more deregulated, global player labour market.

- Deeper competitive inequalities between the richest clubs and the rest. 
- $\quad$ A global market in football-related products, such as team shirts, hats and other apparel.

- $\quad$ Partnerships between global brands and leading players, clubs, and associations.

- $\quad$ Leading European stadiums as all-seated venues with extensive high-tech and highprice security systems.

- $\quad$ Global social media channels between fans and players, clubs, officials, and sponsors. - $\quad$ 'New' audiences for football at national and global levels, notably across women, the new middle-classes, and transnational television viewers. ${ }^{1}$

These processes have not occurred uniformly across different nations, regions and competitions. Notably, the World Cup finals, 'Champions League' (Europe's leading club tournament) and the 'Big 5' European football leagues (England, Spain, Germany, Italy and France) have experienced the most profound changes, particularly in commercial growth and in reaching global television audiences.

The broad transition of top-level football into a more globalized, commercialized, securitized, mediatized, and postmodern sport has been contested in different ways by critical fan activism. Two interrelated social processes - relating to reflexivization and politicization - underpin this critical fan engagement. Reflexivization registers how social actors continuously engage in critical reflection and practice with respect to their diverse circumstances, social relations, resources, and future possibilities. In reference to broader sociological debates about late-modern reflexive modernization (e.g. Beck et al., 1994, Beck et al. 2003), the notion of reflexivization refers here to the capacity of football fans to act as critically reflective agents, in critically scrutinizing the political, economic, social and cultural aspects of football (Numerato, 2015; 2018). Reflexivization facilitates politicization, wherein

\footnotetext{
${ }^{1}$ On these points see for example Giulianotti and Robertson (2009) and also the introduction to this Special Issue by Giulianotti and Numerato.
} 
social actors within football and other cultural fields participate in a plethora of vibrant political issues, debates, and conflicts.

Reflexivization does not a priori result in politicization. Processes of commodification, mediatization and globalization inter alia draw supporters into lifeworlds and relationships that are associated with consumerism and consumption, for example in buying football shirts and apparel, match tickets, stadium food and drink, DVDs, and pay-TV subscriptions. Many fans take critically pragmatic views of these processes, as being both excessive yet unstoppable components of the commercial 'taken-for-granted' world of elitelevel football; this pragmatic reflexivity often leads towards passive rather than active relationships to football politics (Giulianotti, 1999).

Reflexivization resulting in politicization is evidenced in the growth of politicallyengaged fan movements in European football, including through media (such as in 'fanzines' and social media), independent supporter associations and movements, issue-based campaigns, and public demonstrations. Major issues raised and contested by fans include:

- the perceived excessive commercialization of football, as evidenced by high ticket prices, inequalities in ticket allocation, changing kick-off times to suit television schedules, the constant changing of high-priced team kits and other merchandise, and attempts by club owners to change important club symbols such as team colours, and club and stadium names, to attract new fans and sponsors;

- restrictions by security and other club personnel on fan activities, such as through regulating the unfurling of fan banners, blanket use of CCTV technology, body-checks and other intensive security measures at entrances, regulating the freedom of movement of fans travelling for away games, the control of pyrotechnic displays, or seeking to stop fans from standing to watch games;

- mismanagement and corruption among leading football officials; 
- growing competitive inequalities at club and national levels due to financial divisions. ${ }^{5}$

Together, reflexivization and politicization provide the crucial components for fan activists to engage critically with their positioning as consumers and citizens within the game. These forms of critical engagement lead many football supporters explicitly to distinguish themselves from 'consumers'. Their core argument is that the supporter identity within football is defined by deep forms of identification and senses of belonging towards a specific club and its community of fellow supporters, rather than by the market-based consumption of a club product or service (Giulianotti, 2005; Kennedy and Kennedy 2007; King 1998). This critical engagement is often articulated through 'Against Modern Football' initiatives (Hill et al., 2016; Numerato, 2015; Webber, 2015).

This explicit resistance to market logic within football was evidenced in many ways during our research, such as through the popular hashtag \#supportersnotcustomers circulating on social media; and, numerous comments at fan congresses and meetings. For example, as one fan from Bologna stated during a speech at the Football Supporters Europe (FSE) Congress:

They [the football authorities and club owners] are trying to destroy organized supporters, to destroy the enjoyment and to transform us into consumers. It is a fight for our existence and the only way to survive is to unite and fight against it.

(Field notes 4 July 2014, Borgo Albergati)

Similarly, one English fan elaborated on this theme, to critique the market-focused manipulation of stadium atmosphere:

Clubs like to adopt the language of the boardroom and continually refer to us as customers. Clubs are no longer institutions. They are projects. They are increasingly 
trying to manage how we respond and when we should respond as supporters. This can be seen in its most banal incarnation through the enforced jollity of music being played over the tannoy when a goal is scored, thus drowning out the natural outburst of celebration that is released from a crowd. ${ }^{6}$

The criticism of fans is not exclusively led by anti-consumption discourses and sharp distinction from consumer identities. A broader point to be made is that the emergence of reflexive and politicized football supporters is part of a wider set of social processes that are marked by the increased appearance of critical actors in different spheres of consumption, such as in financial services, electronics, fashion, cuisine, and sport. ${ }^{7}$ We turn now to examine the making of this 'citizen-consumer' in more detail.

\section{Citizenship, Consumption and Supporters}

In broad terms, we understand citizen-consumer (or citimer) identities as falling into two ideal-type yet socially interconnected categories, which we differentiate by their respective emphases on the citizen or consumer components. First, the bottom-up citizen-consumer identity is the most familiar and prominent type of citimer, and registers how social actors operate as citizens (including, in some cases, as activists) within contexts that feature social relations of consumption (cf. Gabriel and Lang, 2015). These reflexive social actors are often motivated by social and ethical principles, relating to identities, communities, environmental sustainability, human rights, social solidarity and global justice, which are exercised in part through forms of critical, ethical or political consumerism, and manifested in for example Fair Trade campaigns, anti-sweatshop protests, slow food movements, or lobbying by environmental groups against the oil and motor industries (Forno \& Graziano 2014; García 
Canclini, 2001; Johnston, 2008; Jubas, 2007; Littler, 2009; Micheletti, 2003; Parker, 1999;

Sassatelli, 2004, 2006; Warde, 2015).

Second, in contrast to the bottom-up citimer, the top-down citizen-consumer identity is registered in how major organizations (such as large private companies, governmental bodies, and mass media) represent individuals and social groups more as consumers than as citizens. This aspect has received critical scrutiny particularly in how, within neoliberal social contexts, "citizens are addressed and treated as consumers of public services" (Clarke et al., 2007: 7). The neo-liberal citizen-consumer is thus portrayed as a responsible and selfgoverning agent, choosing freely between offered market services that take the place of the welfare state, for example over pensions, education, care for the elderly, and health care (Derkatch and Spoel, 2015; Tritter and McCallum, 2006), as well as in the areas of media and communication regulation (Livingstone et al., 2007) or even ethical consumption (Cabrera and Williams, 2012). Critical social scientific perspectives highlight how neo-liberalist discourses stress market imperatives within citizen-consumer identities, to the extent that citizenship is redefined in consumerist terms. Thus, from an ethical, social and political perspective, citizens appear as politically constrained rather than enabled and empowered by their market identities.

These bottom-up and top-down ideal-type versions of the citimer are, at everyday level, socially interconnected, and give rise in turn to often fluid citizen-consumer positions, perspectives and identities. These interconnections are highlighted by reflexive and politicized football supporters. On one hand, the political agency of these supporters extends to protests, demonstrations, boycotts, lobbying, and generalized campaigning, as active citizens within the game. On the other hand, these fans demonstrate how citizenship imprinted into critical consumption will never be entirely free from the structures and ideologies of neoliberal consumerism. 
Certainly, there are significant variations between different fans and fan groups in terms of their citizen-sided politics and critical relations with consumption. For example, even among the more politicized fans, we find that many do not 'boycott' their club or the game in protests over different issues, but still continue to buy team merchandise, match tickets, and sports television subscriptions. In addition, some supporter political strategies, such as public relations campaigning, by their very technical nature, have been increasingly materialized in the same way as the global football 'product' that these fans would aim to criticise. ${ }^{8}$ Additionally, a wider set of fans are latently politicized, in that their critical reflexivity does not translate into political action, while the game continues to be viewed as a mere sphere of leisure. Moreover, as we explain, different types of football fan are well aware of their links with consumerism and, while they may be critical of commodification, they may also draw

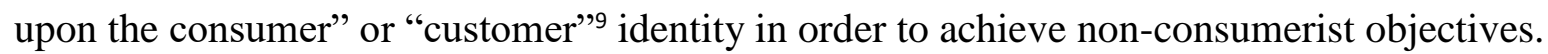

Our concern here is not to highlight and to reinscribe the consumption/citizenship binary opposition. We develop instead the concept of citimer in order to explore the interrelated operating logics of consumption and citizenship. In football, citimers are interested in shaping the game's contemporary culture, and critically engaging with the very logic of consumption, from which, within an increasingly commodified sport that operates across neoliberal societies, they can never be totally separated. Therefore, citizenship and consumption are not represented as two distinct but as two interlinked spheres. The prefix citiexpresses how these fans would identify themselves, as citizens within football culture and also society more broadly; the suffix -mer expresses the consumer logic that they would prefer to avoid, yet within which they have to live.

Based on these premises, we examine the key constellations between citizenship and consumption in contemporary football culture and, through our empirical analysis of football fans' engagement with consumption, we develop critically the citimer concept. By 
emphasising the simultaneous complementarity and interconnections of bottom-up and topdown processes in the making of the citimer, we further explain the modalities of fan engagement and reveal how these processes co-create citimer identities.

\section{Methods}

The data in this paper was collected as part of a wider research project which investigated contemporary reflexive action and its impact on the social world. The case of football fan activists, who critically engage with contemporary football culture, was used as the empirical field of study for investigating these broader reflexivization processes. Our theoretically grounded analysis indicated that the critical engagement of football fans is frequently intertwined with the politics and social relations of consumption. A further explorative approach revealed how consumption serves both as an object and as a vehicle of citizenship. In considering these analytical outcomes, we began to conceptualize the two discursively and analytically opposed spheres of consumption and citizenship as interconnected. In turn, this inspired our more active and systematic engagement with the citizen-consumer concept, and directed us towards the critical development of the concept of citimer.

The research was carried out as a multi-sited ethnographic study both online and offline, across three different national locations - Czech Republic, England and Italy - as well as at the transnational, European level, including further observational work in Germany and Northern Ireland. The selection of European different locations allowed us to observe the citizen-consumer dynamics across different sites in the global football system, from core nations such as England and Italy - where, especially in England, heavily commodified structures through the game also encounter institutionalized and recognized forms of supporter activism - to semi-peripheral nations and regions such as the Czech Republic, 
where elite football has significantly lower but growing emphasis on commodification alongside the less institutionalized and less recognized critical voices of supporters.

The empirical evidence consisted of interviews, observations, and primary and secondary documents. A total of 78 semi-structured interviews were conducted with football fans, supporter liaison officers (SLO), ${ }^{10}$ representatives of football clubs and governing bodies, and policy-makers and political representatives responsible for sport and in particular football notably on security issues and policing. Dozens of further, informal chats were conducted with these research groups at various football-related events, such as demonstrations, congresses, workshops, conferences, meetings or matches. 250 hours of participant observation was undertaken primarily with different fan groups inside stadiums and in other key gathering-places for supporters, for example in meetings, pubs, streets, homes, and virtual venues such as online message boards. Data collection took place mainly between October 2013 and January 2015, with additional interviews and observations carried out afterwards. Direct data evidence was further complemented with the review of constantly gathered primary and secondary documents, totalling 450 textual items, comprising policy papers, mass media and fanzine articles, football fan group statements, and discussion-threads on online football message boards. Audio data from interviews as well as the field notes and documents were analysed using NVivo 10 software. The initial open coding of data was followed by axial and selective coding that in the latter stages contributed to the critical development of the citimer concept.

Our methodological contribution to existing scholarship on the citizen-consumer is twofold. First, this research is based mainly on a symmetrical approach that gave equal attention to football fans and football clubs representatives. In other words, the focus was not only on critically engaged football fans but also on the dynamics between them and football and political authorities. Second, we combined textual evidence with the observation of real 
social life 'in the making'. In this vein, the evidence gathered through direct engagement with the field and through the review of materials was indispensable for understanding the meanings and identities that fans and football authorities attribute to consumption and citizenship in the context of the game.

\section{Blurring consumption and citizenship}

In the complexity of social relations within football, the position of the activist or wider citizen cannot entirely escape the gaze of mediatized consumption. Supporters take specific 'citimer' positions often in circumstances that are not of their choosing. Our further analysis is based on the assumption, following Jubas (2007, p. 250), that "the citizen-consumer is both a subject in society and subjected to social forces" that this social actor is unable to control. Feeding into the ontological tension between enablement and constraint, we have the dual ways in which the citimer identity is constructed, from below (through the lifeworld of fan groups), and from above (through the system of powerful organizational stakeholders within football). We examine these dual processes in turn in the following two sections.

\section{Making the football citimer from below}

The 'bottom-up' links between citizenship and consumption which create the citimer from below are articulated in three particular dimensions: first, in the mainly strategic usage and acceptance of the language of consumption; second, in the transformed repertoire of contention employed by critical football fans and their increasingly formalized practices and actions; and third, through the institutional linkages of citimers with the sphere of consumption.

First, where the football citimer accepts consumption-related language, this approach may point to a pragmatic recognition of the inescapability of consumerism within the game. 
In some contexts, critically engaged fans define themselves as consumers in order to find further support for their citizenship position within the game. They do so for two reasons: to highlight the uniqueness of football fan 'consumers' in regard to their loyalty and commitment to their cultural 'business' in which they are constantly spending their money; and, to argue that fans have the same citizen rights as any consumer, in terms of defending their interests and giving voice to their views on football officials and club owners. These points are illustrated by an Italian fan who argued that supporters should exercise rights that are similar to those of bakery customers:

If you would like to set up the norms, laws that are related to bakeries, it is strange that you do not listen to those who make the bread and who buy it... In football, the following thing happens; you have owners who govern their own societies as if these were their properties because they say: 'I put my money in there', and on the other hand, you get clients who have to pay only with having no rights to say anything.

(Interview, 4 December 2013, Rome, Italy)

A further example of this self-definition of 'citizen as activist consumer' arose at the Supporters Summit, organized by the Football Supporters Federation and Supporters Direct in the UK. During the event, Twitter messages were projected onto a screen behind the speakers; one of these messages read, "Supporters could be the strongest consumer group in the country if only they organised themselves. A big if!" (Field notes 26 July 2014, London). Moreover, the use of consumer discourse relates not only to consumption per se, but also to a wider family of terms and phrases, such as 'the match-day experience', 'the brand' or the 'product' that the English Premier League in particular seeks to sell, particularly to 'new markets' abroad. These terms are not internalized and aired in an uncritical way by supporters; instead, they are used within the rhetorical strategies of football fans in their encounters with club officials and authorities, for example in order to increase the legitimacy of their voice, to 
reduce the risk of an unnecessary conflict escalation resulting from radically different standpoints, and also to attract new fans who could join their cause.

Second, the critical engagement of football citimers is frequently reinforced by the practices that are, somewhat paradoxically, rooted in the consumption-focused logics of the elite professional game which these fans otherwise seek to contest. Fans express their discontent not only in established public ways - such as through fanzine articles, displays of banners, chants and demonstrations - but also through corporate-like public relations strategies, surveys, organized workshops, congresses and conferences, most of which are significantly enhanced by the application of digital technologies. The Supporters Summit organized regularly in the UK, or European Football Fan Congress organized at different locations in Europe, represent two of many possible examples of workshops and congresses that were staged during our two-year project on football activism.

The use of formal discourses around consumption can empower the position of fans vis-à-vis the game's strongest stakeholders, such as football governing bodies, leading clubs, major media corporations and sponsors. By defining themselves as consumers, supporters gain more recognition and legitimacy for their specific campaigns. This improved status serves not only to strengthen the articulation of football fan consumer rights, but also allows supporters to articulate their concerns related to decision-making processes, and commercial, media, policing and wider security issues. In turn, such a stance enables 'consumer' fans to secure a stronger and more recognized position as 'citizens', in that they are much more likely to be engaged with, or even to be approached by, more influential stakeholders in the game, rather than if these supporters had continued to be seen as amorphous, spontaneous, and even uncontrollable sport crowds.

This discursive adoption is not universally supported by fans because it can be at odds with the citizen identity that is essential to their reflexivity and politics. Some fans emphasise 
that any accommodation of marketing and PR language disrupts their identities and the authenticity of football fandom. For example, the Football Action Network, founded in 2015 in the UK, distinguished itself from Supporters Direct and the Football Supporters Federation whose independence is considered to be compromised by financial support and other close links with the government, Football Association (FA) or English Premier League (Field notes 15 March 2015, London). Similar processes could be observed in the Czech Republic, Italy and wider European levels, as many critical fan groups would not engage discursively or socially with football officials or sponsors (Field notes 7 June 2014, Genova; 3 May 2014, Prague; 3 July 2015, Belfast,).

Third, the football citimer develops institutional links with the sphere of consumption. More specifically, fans not only adopt the language of consumption but they also liaise with consumer protection agencies or address relevant authorities in order to push their cause through legal actions. The introductory example of this paper shows how fans liaise institutionally with sponsors - actors who are otherwise integral to the commercial culture that the critically engaged fans contest.

Partnerships with consumer protection agencies represent another strategy of recognition that supporters follow, formally as consumers, but with the underlying political driver as citizens. An example of the encroachments between supporters and consumer protection agencies can be given by the case of the Football Supporters' Federation who were consulted by Ofcom (the UK competition regulator for the communication industries) with respect to issues such as kick-off times, the number of matches televised live, or the principle of the collective selling of audio-visual rights by the English Premier League. ${ }^{11}$

Institutional acceptance of the gaze of consumption can be further exemplified by the controversy surrounding the Tessera del Tifoso (Supporter Identity Card) in Italy, introduced 
by law in 2009 , which required football fans to obtain specific identity cards in order to buy tickets for matches, particularly away games. The scheme was opposed by the heterogeneous movement of critical Italian football fans, including the moderate and legally-focused association Federsupporter. This association addressed Codacons - the Italian organization that coordinates associations which seek to protect the environment and the rights of users and consumers - to oppose one particular aspect of the Tessera del Tifoso: the fact that the identity card was exclusively issued in the form of a credit card. This meant that the card was tied to a bank account, and thereby served the interests of banks rather than supporters, despite the official discourse that emphasized the benefits of the membership scheme and obscured its commodified nature (Field notes 4 December 2013, Rome) and its role in policing of fans (Guschwan, 2013). Thanks to the alert made by the association conjointly with Codacons, the regional administrative court of Lazio declared that the banking requirement was "a commercially incorrect practice". ${ }^{12}$

To sum up, the making of the football citimer from below involves the adoption of consumer discourses and practices as well as institutional liaisons with the sphere of consumption. By these means, football citimers strengthen the credibility and legitimacy of their citizenship initiatives.

\section{Making the football citimer from above}

Similar to the bottom-up link between consumption and citizenship, the top-down formation of the football citimer takes place through the use of language, social practices and institutional links that are adopted and developed by football officials. These officials not only reply to the objections raised by critical football fans, they also co-create the structures in which the collective efforts of supporters are expressed. The making of the football citimer 
from above is dichotomous: it can contribute to the creation of opportunities for a stronger articulation of citizenship, but may also colonize citizenship ideals through the logic of consumerism.

First, the making of the football citimer from above arises through the language adopted by football officials - language that has increasingly reflected the citizenship component of the fan citimer. A potent statement in this regard was made by an Italian football official to his counterparts on two different occasions during our research, that "the football club is not just a brand", to emphasize the social and community contributions of clubs (Field notes 17 October 2014, Rome; 2 December 2014, Florence). Numerous complementary observations and interactions would suggest that these statements were more than rhetorical, as they followed from intensive discussionsT and incorporations of fans' views in decision-making processes (e.g. field notes 24 May 2014, Milan; 5 June 2015, Ancona; 3 July 2014, Bosco Albergati). However, we recognize that similarly strong claims on the social nature of football were rather isolated in contemporary football governance that is heavily dominated by market logic.

The perspective beyond consumption is still in line with broader transformations that construct fans as active citizens as well as consumers. Among these discursive recognitions are notions of match-day experience or fan engagement that stress the supporter's subjectivity. Although usage of this empowering discourse can be critically viewed as a commercial vogue -imported into football from market concerns with customer experience or consumer relations- its function in making the football citimer cannot be totally discounted. Our analysis indicates that the active usage of terms like 'fan engagement' can also serve to develop and to stimulate citizenship initiatives. This impact occurs when discussions of fandom are intertwined with wider social objectives, such as tackling discrimination (Field notes 22-23 October 2014, London) or social and environmental sustainability. ${ }^{13}$ Moreover, 
these instances point to how fans become more critically reflexive on the interface of topdown and bottom-up processes that construct them as citizen-consumers. For example, discourses of sustainability occasionally extended fans' critical and political awareness of the environmental impacts and other externalities of football.

In contrast, the second dimension of the making of the football citimer from above, relates to the social practices of football officials, specifically in considering supporter citizenship but in ways that are redefined from a consumerist perspective. In broad terms, these football official practices appear as forms of strategic appropriation or 'recuperation' of fan language and culture (cf. Debord, 1984). These strategies arise particularly when football officials continuously reinterpret the primarily citizen-related claims of fans. These situations create tensions wherein citizenship side of the citimer is supplanted by the consumption side.

These top-down strategies tend to follow supporter critiques of football from citizen perspectives, such as over lack of democratic governance, and on stadium policing and security. The unforeseen events that accompanied the introduction of SLOs across European football clubs exemplify this logic. Despite the original aim of SLOs to promote dialogue and inclusion among fans in decision-making processes, public debate on the role of these officers emphasized the commercial benefits for football. On one hand, the SLO Handbook of UEFA (European football's governing body) stated that:

This SLO project acknowledges that supporters are not defined by their role as consumers in the professional football system.... supporters should be taken more seriously because they are the major long-term 'cultural investors'. Involving them and their feedback in decision-making processes will help clubs make better choices.

(UEFA, 2011: 6) 
On the other hand, a senior UEFA official whom we interviewed justified the implementation of SLOs in consumption-related terms, as a crucial tool to understand markets: "If there are no established relationships with supporters groups, you do not understand your market..." Similarly, a workshop organized in Italy to promote the implementation of SLOs, was opened and framed by a presentation from a corporate consultancy company that portrayed fans as customers, quoting statements made by the leading expert on call centres, John Anton, or by making reference to the Customer Charter of Manchester United (Field notes 22 May 2014, Milan).

Organized supporter groups are usually highly reflexive here, contesting the ways in which their language, culture and politics are colonized and 'marketized'. As one English fan informed us, "after about three years they [football officials] started to use our language and started to talk our language, about the long term commitment with the clubs ... but this was obviously rhetorical" (Interview, 7 November 2014, Brighton).

Third, the making of the football citimer from above takes place through the development of institutional linkages between fans and clubs. Football clubs and associations reinforce the institutional environment that should promote the citizenship of supporters. However, the actual realization of this institutional tool does not adhere to the original primacy of citizenship; the examples of Supporter Trusts and Fan Ombudsman illustrate this point.

As non-profit football fan organizations that are recognized across Europe, Supporters' Trusts represent a prototype of fan citizenship and inclusion in football governance. Their rationale is to include fans as legitimate stakeholders in the game, guaranteeing access to club decision-making processes. However, this citizen role of Trusts has at times been co-opted by commercial interests and logics, to the extent that these bodies function as extensions or substitutes for club marketing departments, for example by gathering data or advising on fan 
merchandise preferences (Field notes 10 February 2014, Prague; 14 March 2014; Doncaster, 23 October 2014, Nottingham; 14 June 2014, Ancona).

Similarly, the Fan Ombudsman, introduced by the Czech Football Association in 2014 after episodes of supporter violence, was explicitly intended to give voice to diverse fans. During the planning stage for the role, early discussions between fans and football authorities focused on how the Ombudsman would engage in dialogue and communication; however, when put in place, priority was instead accorded to the role's commercial benefits and contribution to stronger policing of supporters (email correspondence with a Czech SLO, 11 December 2014). In this regard, the President of the Czech Football League suggested: “I would like the institution to communicate continuously with different groups of fans and to elicit feedback from them. Our fan is our customer and this will be our customer care line." ${ }^{14}$ Such an approach would obviously equip the fan with citizenship rights only within social relations of consumption.

To sum up, the making of citimer fan identities is driven by a highly commodified football culture which rearticulates citizenship imperatives in the context of market logic. While fan reflexivity cannot be ignored, this voice is redefined and reinterpreted within the domain of consumerism.

\section{Discussion and Conclusions}

The prefix citi- and the suffix - mer, together constituting the citimer category, enable us to set out some of the meanings inherent to the citizen-consumer notion. Here, we have examined how the term citimer captures the empirical nuances related to two conceptualizations of the citizen-consumer: the citimer as made from below and from above. 
Although the 'engagement from below' aspect is crucial to conceptualizing the citimer, the making of the citizen-consumer from above cannot be ignored. The citimer thus appears as a reflexively engaged citizen whose behaviour is not necessarily or exclusively steered by neoliberal agendas. In this vein, the actions of citimers may not be driven by neoliberal philosophy. Instead, they commonly take advantage of political themes and discourses within neoliberalism in order to advance a citizen-consumer agenda. In other words, although not substantially embracing the neoliberal ideology, by adopting consumerlike language, or by creating institutional linkages, supporters can strategically appropriate aspects of top-down responsibilization in order to reach their objectives, including those that are directly in conflict with neoliberal credos.

While the making of the football citimer from below prioritizes citizenship and, due to the hyper-commodification of football, can never be totally separated from consumption, the making of the football citimer from above prioritizes consumption that, due to contemporary reflexivization processes, can never be separated from citizenship. Disentangling the complexities of citizen-consumer constellations, we find that it is not only against but necessarily also through and in consumption that citizenship claims are made. In other words, supporters express their citizenship not only against the consumer gaze imposed on them by institutions, but also from a consumer position, as actors who pay their way into stadiums for fixtures. Taking the consumer stance allows supporters to receive better treatment in their consumption practices and, most importantly, opens up more space for the expression of citizenship claims through their consumption practices.

The ironic interdependence of two theoretically 'binary opposite', citizen and consumer identities can be observed outside of the sphere of football and addressed in terms of conceptual con/fusion (Jubas, 2007). While the empirical basis for our discussion has centred on football, this analysis of the citimer concept has strong applicability for wider 
studies of sport, and many other spheres within the arts or cultural industries. These spheres are not primarily consumption-related, however their penetration by modalities and discourses of consumption has steadily intensified over time, and has been subject to processes of globalization, commodification, securitization, mediatization and postmodernization that we identified in football. We would hypothesise that the levels and varieties of reflexivization and politicization within these spheres will also increase in future.

For these reasons alone, further studies would do well to extend the citimer category into these spheres, and to examine critically its manifestation vis-à-vis the twin themes of citizenship and consumerism. This future work would benefit from juxtaposing the citimer with the 'prosumer' (producer/consumer), to examine how citimers engage in forms of production as well as consumption within football and other cultural fields (cf. Ritzer and Jurgenson, 2010); and, also with wider political debates on post-democracy, to explore how citimers may serve to reinvigorate participatory politics within commercialized spheres of popular culture such as football (Crouch 2004).

We might expect that the latent politicization of otherwise reflexive, yet until now politically passive supporters, will increase. The emergence of citimer identities can be further fostered by both 'from below' and 'from above' processes. In this regard, some attempts to foster environmentally responsible citizenship may stimulate the further politicization of fans and the identification of social, political or economic issues that might otherwise be obscured. These comments apply in the sphere of sport as well as outside. They point to ways in which, within de-politicized post-democratic contexts, different spheres of consumption may constitute key spaces for re-politicizing social life, providing platforms upon which new forms of citizenship are constructed and expressed. 


\section{Acknowledgements}

This article presents research undertaken as part of the project 'Football fandom, reflexivity and social change' (FANSREF), funded by a EC Marie Curie Fellowship (FP7-PEOPLE2012-IEF). Thank you to the interviewees for their insights, time and availability. We would like to thank the anonymous reviewers for their insightful and helpful comments on earlier versions of this article. Different drafts and significant aspects of this paper were presented: at the $12^{\text {th }}$ European Sociological Association Conference in Prague in August 2015; through an invited paper to the 'Soccer as a Global Phenomenon' conference at Harvard University in April 2016; and, through a further invited paper to Harvard University, April 2017.

\section{Notes}

1 https://twitter.com/spiritofshankly/status/564054547002560513

2 http://www.liverpoolecho.co.uk/news/liverpool-news/premier-league-sponsor-barclaysbacks-9813736

3 http://www.bbc.com/sport/football/35764007

4 The campaign started in 2013 as a protest against the high tickets price for away fans, which reached up to $£ 60$ for a match. The aim was to set a price cap at $£ 20$ (http://www.fsf.org.uk/campaigns/twentys-plenty/).

5 On these processes see for example Guschwan (2012), Kennedy and Kennedy (2007), Millward (2012), Numerato (2015; 2018), Turner (2013), and Urban Studies (2011).

$6 \mathrm{http}: / /$ dispatchesfromafootballsofa.com/2014/05/19/how-we-can-change-football/.

7 For the sake of precision, we recognize that citizen-consumer practices are not unique to the late 20th and early 21 st centuries. Consumer movements were evident in the late 19th century, for example consumer co-operatives, women's cooperative guilds, and feminist movements that used consumption to articulate political rights (Jubas 2007; Hilton 2005).

8 The empirical evidence suggests that fan activism is backed by marketing, mass media and political expertise that supporters accumulate in their non-sport careers, and which they apply in relation to football as leisure. Although rather rare, some sport journalists are fan activists and bring their critical agenda into mainstream mass media (e.g. field notes 15 April 2014, Prague; 15 June 2014, Ancona; 10 September 2014, London).

9 By way of definition, a 'customer' is someone who buys a product or service, while a 'consumer' uses a product or service (even if not bought). However, in modern or 
postmodern usage, the meanings of 'consumer', 'consumption' and 'consumer culture' tend to be much more fully tied to market contexts, to the 'use' (practical) and 'exchange' (symbolic) values of purchased products and services, and to the social relations and cultural meanings that surround these products or services.

10 SLOs were compulsorily introduced from the 2012/13 season onwards across all clubs competing in competitions controlled by the European football governing body, UEFA. The primary role of SLOs is to mediate communication and dialogue between clubs and fans.

11 http://www.fsf.org.uk/assets/Downloads/News/2014/FSF-Response-to-Ofcom-December2014.pdf

12 http://www.federsupporter.it/index.php/242-tessera-del-tifoso-labbinamento-fra-tesseradel-tifoso-e-carta-di-credito-ricaricabile-integra-una

13 The focus on sustainability was on some occasions articulated with respect to travel to away fixtures. For example, the campaign by Serie B (the second professional division in Italy) to promote travel to away fixtures, included substantial messages on environmental responsibility, sustainable tourism and the celebration of local products messages on critical consumption that would potentially appeal in particular to the habitus of new middle class fans (Field notes 2 December 2014, Florence). Similarly, in England, football officials and fans publicly debated the need to support rail transport on environmental grounds (Field notes 22 October 2014, London)

14 See http://m.rozhlas.cz/zpravy/fotbal/_zprava/facr-pracuje-na-databazi-problemovychfanousku-a-chysta-ombudsmana--1367193

\section{References}

Appadurai A (1990) Disjuncture and difference in the global cultural economy. Theory, Culture \& Society 7(2): 295-310.

Bauman Z (1992) Intimations of Postmodernity. London: Routledge.

Beck U, Giddens A and Lash S (1994) Reflexive Modernization: Politics, Tradition and Aesthetics in the Modern Social Order. Cambridge: Polity Press.

Beck U, Bonss W and Lau C (2003). The theory of reflexive modernization: Problematic, hypotheses and research programme. Theory, Culture \& Society 20(2):1-33.

Cabrera S and Williams CL (2012) Consuming for the social good: Marketing, consumer citizenship, and the possibilities of ethical consumption. Critical Sociology 40: 349-367.

Clarke J, Newman J, Smith N, et al. (2007) Creating Citizen-Consumers: Changing Publics and changing public services. London: Sage.

Crouch C (2004) Post-Democracy. Oxford: Polity Press.

Deacon D and Stanyer J (2014) Mediatization: key concept or conceptual bandwagon? Media, Culture \& Society 36(7): 1032-1044.

Debord G (1984) Society of the Spectacle. New York: Black \& Red.

Derkatch C and Spoel P (2015) Public health promotion of 'local food': Constituting the self- 
governing citizen-consumer. Health. Available from:

http://journals.sagepub.com/doi/pdf/10.1177/1363459315590247.

Forno F and Graziano PR (2014) Sustainable community movement organisations. Journal of Consumer Culture 14(2): 139-157.

Gabriel Y and Lang T (2015) The Unmanageable Consumer. London: Sage.

García Canclini N (2001) Consumers and citizens: globalization and multicultural conflicts. Minneapolis: University of Minnesota Press.

Giulianotti R (2005) Sport spectators and the social consequences of commodification: Critical perspectives from Scottish football. Journal of Sport and Social Issues 29(4): 386-410.

Giulianotti R (1999) Football: A Sociology of the Global Game. Cambridge: Polity Press.

Giulianotti R and Robertson R (2009) Globalization and Football. London: Sage.

Guschwan, M (2012) Fandom, brandom and the limits of participatory culture. Journal of Consumer Culture 12(1):19-40.

Guschwan M (2013) La Tessera della Rivolta : Italy' s failed fan identification card. Soccer \& Society 14(2): 215-229.

Harvey D (2005) A Brief History of Neoliberalism. Oxford: Oxford University Press.

Hill T, Canniford R and Millward P (2016) Against modern football: Mobilising protest movements in social media. Sociology. Available from: http://journals.sagepub.com/doi/abs/10.1177/0038038516660040

Hilton M (2005) The duties of citizens, the rights of consumers. Consumer Policy Review 15(1): 6-12.

Johnston J (2008) The citizen-consumer hybrid: Ideological tensions and the case of Whole Foods Market. Theory and Society 37(3): 229-270.

Jubas K (2007) Conceptual con/fusion in democratic societies: Understandings and limitations of consumer-citizenship. Journal of Consumer Culture 7(2): 231-254.

Kennedy D and Kennedy P (2007) Preserving and extending the commodification of football supporter relations: A cultural economy of supporters direct. Sociological Research Online 12. Available from: www.socresonline.org.uk/12/1/kennedy.html

King A (1998) The end of the terraces: The transformation of English football in the 1990s. London: Leicester University Press.

Klauser F (2017) Surveillance and Space. London: Sage.

Littler J (2009) Radical consumption: Shopping for change in contemporary culture. Maidenhead: Open University Press.

Livingstone S, Lunt P and Miller L (2007) Citizens, consumers and the citizen-consumer: articulating the citizen interest in media and communications regulation. Discourse \& Communication 1(1): 63-89.

Micheletti M (2003) Why Political Consumerism? When Products Become Political. Basingstoke: Palgrave Macmillan. 
Millward P (2012) Reclaiming the Kop? Analysing Liverpool supporters' 21st century mobilizations. Sociology 46(4): 633-648.

Numerato D (2015) Who says 'No to modern football?' Italian supporters, reflexivity, and neo-liberalism. Journal of Sport \& Social Issues 39(2): 120-138.

Numerato D (2018) Football Fans, Activism and Social Change. London: Routledge.

Parker G (1999) The role of the consumer-citizen in environmental protest in the 1990s. Space and Polity 3(1): 67-83.

Ritzer G and Jurgenson N (2010) Production, consumption, prosumption: The nature of capitalism in the age of the digital 'prosumer'. Journal of Consumer Culture 10(1): 1336.

Robertson R (1992) Globalization: Social Theory and Global Culture. London: Sage.

Sassatelli R (2004) The political morality of food: Discourses, contestation, and alternative consumption. In: Harvey M, McMeekin A, and Warde A (eds), Qualities of Food, Manchester: Manchester University Press, pp. 176-191.

Sassatelli R (2006) Virtue, Responsibility and Consumer Choice. In: Brewer J and Trentmann $\mathrm{F}$ (eds), Consuming cultures global perspectives historical trajectories, Oxford, UK: Berg, pp. 219-250.

Tritter JQ and McCallum A (2006) The snakes and ladders of user involvement: Moving beyond Arnstein. Health Policy 76(2): 156-68.

Turner M (2013) Modern 'live' football: moving from the panoptican gaze to the performative, virtual and carnivalesque. Sport in Society 16(1): 85-93.

UEFA (2011) UEFA Supporter Liaison Officer Handbook. Nyon: UEFA.

Urban Studies (2011) Security and surveillance at sport mega events. Special Issue: 48 (15).

Walsh AJ and Giulianotti R (2007) Ethics, Money and Sport: This Sporting Mammon. London: Routledge.

Warde A (2015) The sociology of consumption: Its recent development. Annual Review of Sociology 41(1): 117-134.

Webber DM (2015) 'Playing on the break': Karl Polanyi and the double-movement 'Against Modern Football.' International Review for the Sociology of Sport. Available from: http://irs.sagepub.com/cgi/doi/10.1177/1012690215621025. 